\title{
Ventricular Ganglioneuroblastoma in an Adult and Successful Treatment with Radiotherapy
}

\author{
Mustafa Akın${ }^{1}$, Şefika Arzu Ergen ${ }^{1}$, Büge Öz ${ }^{2}$, Gülyüz Atkovar ${ }^{1}$, İsmet Şahinler ${ }^{1}$ \\ ${ }^{1}$ Department of Radiation Oncology, İstanbul University Cerrahpaşa Faculty of Medicine, İstanbul, Turkey \\ ${ }^{2}$ Department of Pathology, İstanbul University Cerrahpaşa Faculty of Medicine, İstanbul, Turkey
}

Background: Ganglioneuroblastomas (GNBs) are rare embryonic neoplasms in the spectrum of neuroblastic tumours and $80 \%$ of cases occur in the first decade. In adults, GNBs are usually located in the retroperitoneum, mediastinum and neck but intracranial GNBs are extremely rare.

Case Report: A 34-year-old male applied to the Department of Neurology outpatient clinic with a two month history of headache and numbness in his legs. Detailed examinations and cranial CT were performed and showed a mass with a $5 \mathrm{~cm}$ diameter running from the third to the fourth ventricle. Referral to a neurosurgeon was performed for partial removal of the tumour, as the histological and immunohistochemical studies defined the diagnosis of GNB. Three months later, when the patient experienced dizziness, an MRI was performed, which showed a $4 \times 3 \mathrm{~cm}$ ventricular mass, with hypointense characterisation in T1-weighted and hyperintense characteristics in T2-weighted and flair sequences. Afterwards, fractioned radiotherapy (54 Gy/30 fx) was chosen as the appropriate therapy. In the follow-up period, MRI was performed 3 months and 1 year after treatment, and revealed shrinkage of the tumour by at least $50 \%$. Meanwhile the patient's post-irradiation course was favourable.

Conclusion: Data following the use of radiotherapy as treatment for intracranial GNB showing favourable results has been reported.

(Balkan Med J 2014;31:173-6).

Key Words: Neuroblastic tumour, radiotherapy, ventriculer ganglioneuroblastoma
Ganglioneuroblastomas (GNBs) are one of the members of the neuroblastic group of tumours and it can be differentiated from ganglioneuroma and neuroblastoma. Both mature ganglion cells and undifferentiated neuroblasts can be seen in GNB (1). The presence of immature tissue indicates malignant or potentially malignant behaviour in GNB and $80 \%$ of cases occur in the first decade (2). These tumours are seen in adults at any age and although they are usually located in the retroperitoneum, posterior mediastinum, pelvis, adrenal gland or neck, intracranial GNBs in adults are seen in extremely rare cases (3). In the reviewed literature, we identified only 9 intracranial GNB cases. To the best of our knowledge, this is the first report of a ventricular ganglioneuroblastoma in adults.

\section{CASE PRESENTATION}

A 34-year-old male patient applied to the Department of Neurology outpatient clinic with a two month history of headache and numbness in his legs. After evaluation of the detailed history and the physical-neurological examination of the patient, a number of laboratory tests and imaging studies were ordered. Among these tests, Computed Tomography images of the cranium showed a mass with a diameter of $5 \mathrm{~cm}$ lying from the $3^{\text {rd }}$ to the $4^{\text {th }}$ ventricle. The patient was referred to the Department of Neurosurgery and partial resection of the mass was chosen as the next step. The pathological findings showed fibrovascular tissue, with two distinct elements; mature and immature neuroblastic cells among atypic neuronal cells were detected (Figure 1). Mature and intermediate forms of ganglionic cells had fibrillated cytoplasmic process. The immunohistochemical study showed synaptophysin/Neu-N, neurofilament protein positivity and GFAP negativity (Figure 2). In addition, the high Ki-67 score supported the diagnosis of GNB (Figure 3). Initially, resection of the tumour was accepted as sufficient therapy until 3 months after the operation when the patient experienced symptoms of dizziness. Re-examinations and cranial Magnetic Resonance Imaging (MRI) was performed and a $4 \times 3 \mathrm{~cm}$ ventricular mass showing hypointense characterisation in T1weighted sequences was detected; meanwhile, the mass was 


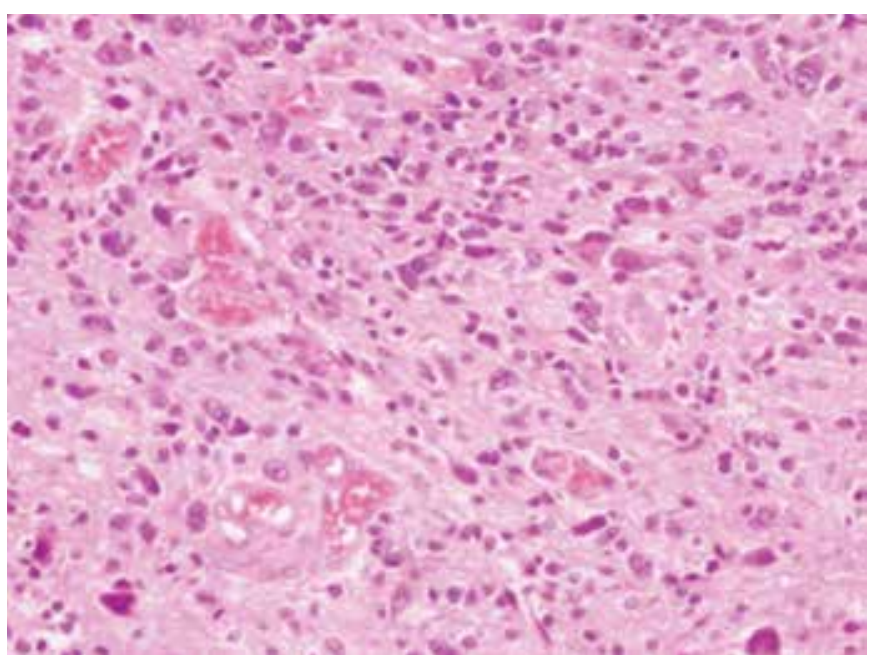

FIG. 1. $(H+E X 400)$ Immature neuroblastic cells among atypical neuronal cells.

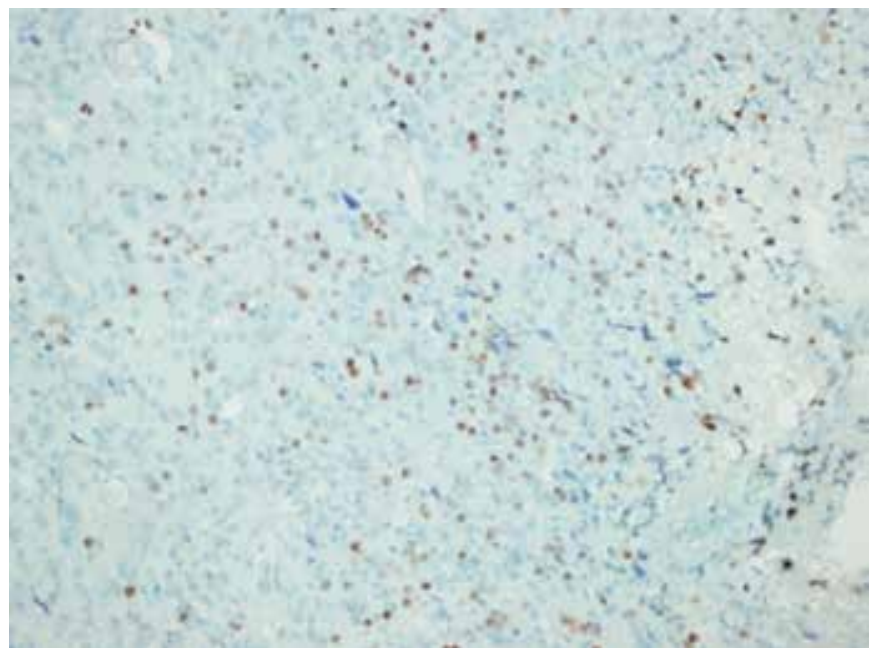

FIG. 3. (Ipx; Ki-67X200) High Ki-67 score.

hyperintense in T2-weighted and flair sequences (Figure 4). At this stage, re-operation was not considered because of the possible side effects, and radiotherapy (RT) was planned as the appropriate treatment. Gross tumour volume (GTV) and organs at risk were contoured manually. Clinical target volume (CTV) was determined by a margin $1.5 \mathrm{~cm}$ from the GTV, and adding $1 \mathrm{~cm}$ to the CTV comprised the planning target volume (PTV). We applied $1.8 \mathrm{~Gy} / 30$ fractions, totalling 54 Gy dose radiation to the PTV, with conformal 3D external RT. During the follow-up period, 3 months after RT, cranial MRI showed 50\% regression of mass according to pre-irradiation. One year later, the patient had no symptoms or signs and there was also no radiological difference between the 3 months and 1 year post-irradiation MRI. Also, the patient signed the informed consent form indicating that they approved publication of the data.

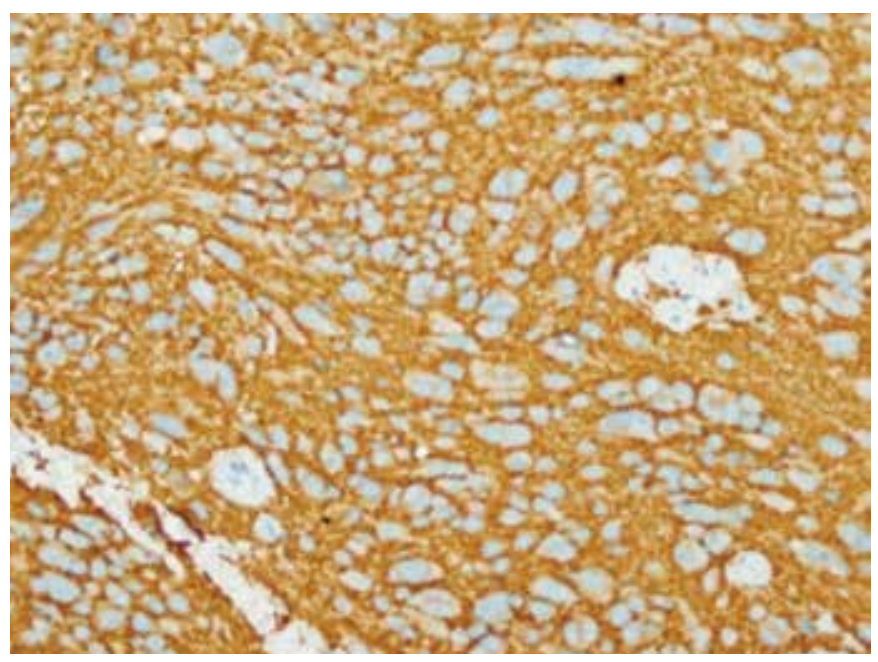

FIG. 2. (Ipx; SynX400) Synaptophysin positivity at background and all tumour cells.

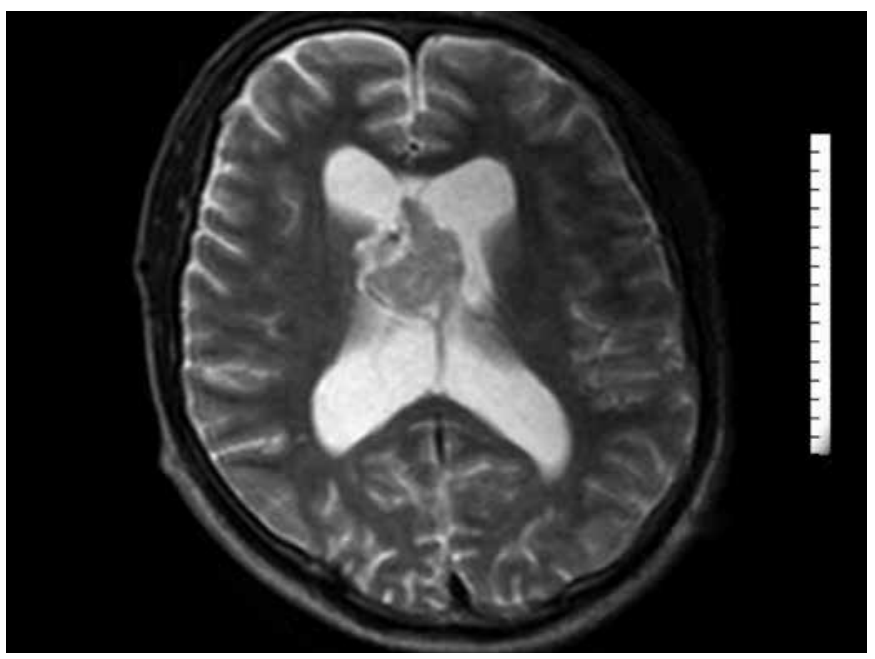

FIG. 4. Neuroimaging of the tumour.

\section{DISCUSSION}

Cerebral embryonic tumours are classified into three categories according to the World Health Organisation (WHO): supratentorial primitive neuroectodermal tumour (PNET), cerebral neuroblastoma and cerebral ganglioneuroblastoma (4). Tumours with a distinct neuronal features are classified as either neuroblastoma or ganglioneuroblastoma depending on the level of neuronal differentiation. Neuroblastomas are more undifferentiated tumours, while a GNB is a tumour that has both mature ganglion cells and neuroblasts together with intermediate forms (5). Similarly, histological examination of the present case of GNB showed highly cellular areas, composed of embryonic cells and consisting of neoplastic neuronal cells with a range of maturation from neuroblasts to ganglion cells, but no glial elements were identified. Immuno- 
TABLE 1. Previously reported cases of adult intracranial ganglioneuroblastoma

\begin{tabular}{|c|c|c|c|c|c|c|}
\hline Authors & Year & Age & Sex & Location & Surgery & RT (Gy) \\
\hline Feigin et al. (6) & 1977 & 27 & M & Brain & - & - \\
\hline Nakazato et al. (2) & 1979 & - & - & Pineal & - & - \\
\hline Pearl at al. (8) & 1981 & 27 & $\mathrm{M}$ & Frontal & PR & 55 \\
\hline Hosaka et al. (9) & 1982 & 19 & $\mathrm{M}$ & Anterior Skull Base & PR & 40 \\
\hline Nakajima et al.(10) & 1983 & 36 & $\mathrm{~F}$ & Frontal & $\mathrm{CR}$ & 10.9 \\
\hline Tanaka et al. (7) & 1999 & 57 & $\mathrm{M}$ & Pineal & $\mathrm{CR}$ & 50 \\
\hline Nakazato et al. (2) & 2004 & 32 & $\mathrm{M}$ & Temporal & - & - \\
\hline Nishihara et al. (11) & 2008 & 32 & $\mathrm{~F}$ & Parietal & - & - \\
\hline Sabatino et al. (12) & 2009 & 60 & $\mathrm{~F}$ & Occipital & $\mathrm{CR}$ & 60 \\
\hline Akın et al. (present study) & 2011 & 34 & $\mathrm{M}$ & Ventricle & $\mathrm{CR}$ & 54 \\
\hline
\end{tabular}

CR: complete resection; PR: partial resection; - : unknown; RT: radiotherapy

histochemical findings also supported a distinctive neuronal nature of this tumour.

The most common sites of origin of GNBs are the adrenal medulla, extra-adrenal retroperitoneum, posterior mediastinum, neck and pelvis, while intracranial GNBs are uncommon (3). Most cases occur before the age of two years, but older children and young adults are also affected. Feigin reported first case of adult intracranial GNB in 1977 (6). Sine then, eight intracranial adult GNBs have been reported. Their locations were temporal lobe, parietal lobe, occipital lobe, two frontal lobes, two pineal glands, and anterior skull base, with one intracranial tumour with no location defined. The gender distribution of the reported cases consists of 5 males, 3 females and 1 unknown gender; the age range was 19-60 years. The applied treatments in the 5 published were surgery with complete resection in 3 cases and partial resection in 2 cases. These patients received radiotherapy (10.9-60 Gy) and the post-irradiation course was favourable in their follow-up period ranging from 5 months to 3 years. Only 1 patient received radiotherapy and chemotherapy with temozolomide (Temodal; Orion Corporation Orion Pharma Tengstrominkatu, Turku, Finland) and remained disease-free for 18 months after diagnosis (12). Our case report provides data of an intracranial ventricular GNB in a 34-year-old man, which was unusual (Table 1) (2, 6-12).

Clinical signs and symptoms of intracranial GNBs are related to their location. Patients present with seizures, dizziness, disturbances of consciousness, signs of increased intracranial pressure, headaches and motor deficits. In terms of differential diagnosis, commonly seen ventricular tumours must be excluded as eligible for our case. These are mostly low grade glial tumours, such as intrinsic brain tumours and colloid cysts, and craniopharyngioma, such as extrinsic brain tumours (13). Also, it is indicated that histologically other embryonic tumours such as ependymoblastoma, pineoblastoma, medulloepithelioma, atypical teratoid or rhabdoid tumour and retinoblastoma are considerable and separable by the presence of solely neuronal tumour cells and immunohistochemical expression of neuronal markers (2). Eventually, this was diagnosed as GNB based on the immunohistochemical and histopathological characteristics.

Regarding the treatment of intracranial GNB, as in all intracranial tumours, the first choice is surgery. The benefit of adjuvant therapy is unclear since it not commonly used. To date, only 5 cases have received adjuvant radiotherapy in the literature search. Here, we irradiated the patient using $1.8 \mathrm{~Gy} / 30$ fractions ( $54 \mathrm{~Gy}$ in total) with conformal 3D radiotherapy. After 3 months, $50 \%$ regression of the mass was determined by comparing MRI sequences. In the follow-up duration, even after 1 year there were no clinical symptoms or radiological differences between the 3 months and 1 year post-irradiation MRI sequences.

Ethics Committee Approval: N/A.

Informed Consent: Written informed consent was obtained from patient who participated in this study.

Peer-review: Externally peer-reviewed.

Author contributions: Concept - M.A., S.A.E., G.A., İ.; Design - M.A., S.A.E., G.A., İ.S.; Supervision - M.A., S.A.E., G.A., İ.S.; Resource - M.A., S.A.E., G.A., İ.S., B.O.; Materials - M.A., S.A.E., G.A., İ.S., B.O.; Data Collection\&/or Processing - M.A., S.A.E., G.A., İ.S., B.O..; Analysis\&/or Interpretation - M.A., S.A.E., G.A., İ.S.; Literature Search - M.A., S.A.E., G.A., İ.S., B.O.; Writing - M.A., S.A.E., G.A., İ.S., B.O.; Critical Reviews - M.A., S.A.E., G.A., İ.S., B.O.

Conflict of Interest: No conflict of interest was declared by the authors.

Financial Disclosure: The authors declared that this study has received no financial support.

\section{REFERENCES}

1. Perez Carlos A, Halperin Edward C, Brady Luther W. Pediatric tumorsneuroblastoma. In: Principles and practice of radiation oncology. 5th edition. Baltimore: Lippincott Williams \& Wilkins; 2008:1860.

2. Nakazato Y, Hosaka N. A 32 year-old man with left temporal lobe tumour. Neuropathol 2004;24:261-2. [CrossRef]

3. Kilton LJ, Aschenbrener C, Burns CP. Ganglioneuroblastoma in adults. Cancer 1976;37:974-83. [CrossRef] 
4. Rorke LB, Hart MN, McLendon RE. Supratentorial primitive neuroectodermal tumour (PNET). In: Kleihues P, Cavenee WK, editors. Pathology and genetics of tumours of the nervous system. Lyon: IARC Press; 2000:141-4.

5. Sibilla L, Martelli A, Farina L, Uggetti C, Zappoli F, Sessa F, et al. Gangliooneuroblastoma of the spinal cord. AJNR Am J Neuroradiol 1995; 16:875-7.

6. Feigin I, Cohen M . Maturation and anaplasia in neuronal tumors of the peripheral nervous system, with observation on the glial like tissues in the ganglioneuroblastoma. J Neuropathol Exp Neurol 1977;36:748-63. [CrossRef]

7. Tanaka M, Shibui S, Nomura K, Nakanishi Y. Pineal ganglioneuroblastoma in an adult. J Neurooncol 1999;44:169-73. [CrossRef]

8. Pearl GS, Mirra SS, Miles ML. Intracerebral ganglioneuroblastoma with intracytoplasmic microtubular aggregates: case report and ultrastructural study. Ultrastruct Pathol 1981;2:337-42. [CrossRef]
9. Hosaka T, Nukui H, Koizumi H, Miyazaki M. Ganglioneuroblastoma of the anterior skull base with a long term follow-up. Case Report. Neurol Med Chir (Tokyo) 1982;22:757-62. [CrossRef]

10. Nakajima F, Kuwabara T, Yagishita S. Primary cerebral ganglioneuroblastoma. Neurol Med Chir (Tokyo) 1983;23: 301-4. [CrossRef]

11. Nishihara H, Ozaki Y, Ito T, Yoshinaga T, Tabu K, Tanino M, et al. A case of cerebral ganglioneuronal tumor in the parietal lobe of an adult. Brain Tumor Pathol 2008;25:45-9. [CrossRef]

12. Sabatino G, Lauriola L, Sioletic S, Puca A. Occipital ganglioneuroblastoma in an adult. Acta Neurochir (Wien) 2009;151:495-6. [CrossRef]

13. Sanli M, Gurkanlar D, Yildiz B, Sekerci Z. Ten years of experience in the surgery of lateral and third ventricletumors. Türk Nörosirürji Dergisi 2003;13:12-7. 